The Journal of $\mathbf{N}_{\text {onlinear }} \mathbf{S}_{\text {ciences and }}$ Applications http://www.tjnsa.com

\title{
SOME COMMON FIXED POINT RESULTS IN NON-NORMAL CONE METRIC SPACES
}

\author{
ZORAN KADELBURG ${ }^{1 *}$ AND STOJAN RADENOVIĆ ${ }^{2}$
}

\begin{abstract}
The aim of this paper is to obtain extended variants of some common fixed point results in cone metric spaces in the case that the underlying cone is not normal. The first result concerns $g$-quasicontractions of D. Ilić and V. Rakočević [Common fixed points for maps on cone metric space, J. Math. Anal. Appl. 341 (2008), 876-882], and the second is concerned with HardyRogers-type conditions and extends some recent results of M. Abbas, B. E. Rhoades and T. Nazir [Common fixed points for four maps in cone metric spaces, Appl. Math. Comput. 216 (2010), 80-86].
\end{abstract}

\section{INTRODUCTION AND PRELIMINARIES}

In 2007, Huang and Zhang [7] reintroduced the concept of a cone metric space, replacing the set of real numbers by an ordered Banach space in the definition of metric, and obtained some fixed point theorems for contractive type mappings. Since then, there has been a lot of activity in this area and several interesting fixed point results have appeared in cone metric spaces (e.g., [1, 2, 3, 7, 8, 9 , 11, 12, 13, 14, 15]). Most of the papers dealt with fixed point results in normal cone metric spaces $([1,2,7,8,9])$. In this paper, unlike other authors, we do not impose the normality condition on cones. Our proofs only require the assumption that the interior of the cone be non-empty (such cones are usually called solid). It is worth mentioning that we neither use continuity of the vector metric $d$ nor the Sandwich Theorem.

Date: Received: 28 Aug. 2010.

* Corresponding author

(c) 2010 N.A.G.

1991 Mathematics Subject Classification. Primary 47H10; Secondary 54H25.

Key words and phrases. Common fixed point; ordered Banach space; cone metric space; normal and non-normal cone; weakly compatible mappings.

The authors are thankful to the Ministry of Science and Technological Development of Serbia. 
The following definitions and results will be needed in the sequel.

Definition 1.1. 6] Let $E$ be a real Banach space. A subset $P$ of $E$ is called a cone if:

(a) $P$ is closed, non-empty and $P \neq\{\theta\}$;

(b) $a, b \in \mathbb{R}, a, b \geq 0, x, y \in P$ imply that $a x+b y \in P$;

(c) $P \cap(-P)=\{\theta\}$.

For a given cone $P$, we define the partial ordering $\preceq$ with respect to $P$ by $x \preceq y$ if and only if $y-x \in P$. We shall write $x \ll y$ for $y-x \in \operatorname{int} P$, where int $P$ stands for the interior of $P$ and use $x \prec y$ for $x \preceq y$ and $x \neq y$.

There exist two kinds of cones, normal and non-normal ones. The cone $P$ in the normed space $E$ is called normal whenever there is a number $k>0$ such that for all $x, y \in E, \theta \preceq x \preceq y$ implies $\|x\| \leq k\|y\|$. For details see [6].

Definition 1.2. [7] Let $X$ be a non-empty set. Suppose that a mapping $d$ : $X \times X \rightarrow E$ satisfies:

$\left(\mathbf{d}_{1}\right) \theta \preceq d(x, y)$ for all $x, y \in X$ and $d(x, y)=\theta$ if and only if $x=y$;

$\left(\mathbf{d}_{2}\right) d(x, y)=d(y, x)$ for all $x, y \in X$;

$\left(\mathbf{d}_{3}\right) d(x, z) \preceq d(x, y)+d(y, z)$ for all $x, y, z \in X$.

The function $d$ is called a cone metric and $(X, d)$ is called a cone metric space.

The concept of a cone metric space is more general than that of a metric space. For basic notions concerning cone metric spaces we refer to [7].

Let $(X, d)$ be a cone metric space. The following properties are often used, particularly in the case when the underlying cone is non-normal, so that some standard tools as the continuity of the metric and the Sandwich Theorem cannot be used. The only assumption is that the cone $P$ is solid, i.e., its interior is nonempty.

( $\left.\mathbf{p}_{1}\right)$ If $a \preceq h a$ where $a \in P$ and $h \in[0,1)$, then $a=\theta$.

$\left(\mathbf{p}_{2}\right)$ If $\theta \preceq u \ll c$ for each $c, \theta \ll c$, then $u=\theta$.

$\left(\mathbf{p}_{3}\right)$ If $a \preceq b+c$ for each $c, \theta \ll c$, then $a \preceq b$.

$\left(\mathbf{p}_{4}\right)$ If $u \preceq v$ and $v \ll w$, then $u \ll w$.

( $\left.\mathbf{p}_{5}\right)$ If $c \in \operatorname{int} P, \theta \preceq a_{n}$ and $a_{n} \rightarrow \theta$, then there exists $k \in \mathbb{N}$ such that for all $n>k$ we have $a_{n} \ll c$.

For details about these properties see [11, 13].

The aim of this paper is to obtain extended variants of some common fixed point results in cone metric spaces in the case that the underlying cone is not normal. The first result concerns so-called $g$-quasicontractions of Ilić and Rakočević [8], and the second is concerned with Hardy-Rogers-type conditions and extends some recent results of Abbas, Rhoades and Nazir [3].

\section{Results}

2.1. Common fixed points of $g$-quasicontractions. The following theorem gives a proper generalization of results from [4, 5, 8, 9, 14, 15] (see Example 2.4 given below). Our main result is obtained without using the normality condition and without making use of the notions of commutativity and continuity. 
Recall the definition of $g$-quasicontractions on cone metric spaces from [8]. Such mappings are generalizations of Das-Naik's mappings from the frame of metric spaces [5].

Definition 2.1. [8] Let $(X, d)$ be a cone metric space, and $f, g: X \rightarrow X$. Then, $f$ is called a $g$-quasi-contraction if for some constant $\lambda \in(0,1)$ and for all $x, y \in X$, there exists

$$
u \in\{d(g x, g y), d(g x, f x), d(g y, f y), d(g x, f y), d(g y, f x)\},
$$

such that

$$
d(f x, f y) \preceq \lambda \cdot u .
$$

It was proved in 8 , using normality of the cone, that $f$ and $g$ have a unique common fixed point in $X$, if $f X \subset g X, g(X)$ is complete, $f$ commutes with $g$, $f$ or $g$ is continuous, and they satisfy (2.1). The normality condition was later removed in the case $g=i_{X}$ in 13 and 15. The case of $g$-quasicontractions under the assumption $0 \leq \lambda<\frac{1}{2}$ was treated in [14].

Theorem 2.2. Let $(X, d)$ be a cone metric space over a solid cone $P$, and let $f, g: X \rightarrow X$ be such that $f X \subset g X$ and $g X$ is complete. If $f$ is a g-quasicontraction, then $f$ and $g$ have a coincidence point in $X$. Moreover, if $f$ and $g$ are weakly compatible, then $f$ and $g$ have a unique common fixed point.

Recall that a point $y \in X$ is called a point of coincidence for mappings $f, g$ : $X \rightarrow X$ if there exists $x \in X$ such that $f(x)=g(x)=y$. Then, $x$ is called a coincidence point. Mappings $f$ and $g$ are called weakly compatible if they commute at their coincidence points.

Proof. The condition $f X \subset g X$ implies that starting with an arbitrary $x_{0} \in X$, we can construct a sequence $\left\{y_{n}\right\}$ of points in $X$ such that $y_{n}=f x_{n}=g x_{n+1}$ for all $n \geq 0$. We shall prove that $\left\{y_{n}\right\}$ is a Cauchy sequence in $X$. Consider two cases.

1. First, suppose that there exists an $n_{0}$ such that $y_{n_{0}}=y_{n_{0}+1}$. Then sequence $\left\{y_{n}\right\}$ is constant for $n \geq n_{0}$. Indeed, from (2.1) it follows that

$$
d\left(y_{n_{0}+1}, y_{n_{0}+2}\right)=d\left(f x_{n_{0}+1}, f x_{n_{0}+2}\right) \preceq \lambda \cdot u,
$$

where

$$
\begin{aligned}
u \in & \left\{d\left(g x_{n_{0}+1}, g x_{n_{0}+2}\right), d\left(g x_{n_{0}+1}, f x_{n_{0}+1}\right), d\left(g x_{n_{0}+2}, f x_{n_{0}+2}\right),\right. \\
& \left.d\left(g x_{n_{0}+1}, f x_{n_{0}+2}\right), d\left(g x_{n_{0}+2}, f x_{n_{0}+1}\right)\right\}
\end{aligned}
$$

Taking into account (2.2), we have to consider the following cases:

$1^{0} d\left(y_{n_{0}+1}, y_{n_{0}+2}\right) \preceq \lambda \cdot \theta=\theta$, which implies that $y_{n_{0}+1}=y_{n_{0}+2}$,

$2^{0} d\left(y_{n_{0}+1}, y_{n_{0}+2}\right) \preceq \lambda \cdot d\left(y_{n_{0}+1}, y_{n_{0}+2}\right) \Rightarrow d\left(y_{n_{0}+1}, y_{n_{0}+2}\right)=\theta$, that is, $y_{n_{0}+1}=$ $y_{n_{0}+2}$

$3^{0} d\left(y_{n_{0}+1}, y_{n_{0}+2}\right) \preceq \lambda \cdot d\left(y_{n_{0}}, y_{n_{0}+2}\right) \preceq \lambda \cdot d\left(y_{n_{0}}, y_{n_{0}+1}\right)+\lambda \cdot d\left(y_{n_{0}+1}, y_{n_{0}+2}\right)=$ $\lambda d\left(y_{n_{0}+1}, y_{n_{0}+2} \Rightarrow d\left(y_{n_{0}+1}, y_{n_{0}+2}\right)=\theta\right.$, that is, $y_{n_{0}+1}=y_{n_{0}+2}$. 
Continuing this process, we obtain that $y_{n}=y_{n_{0}}$ for each $n \geq n_{0}$. Therefore, in this case $\left\{y_{n}\right\}$ turns out to be an eventually constant sequence and hence a Cauchy one.

2. Suppose now that $y_{n} \neq y_{n+1}$ for all $n \geq 0$. We shall show that for each $n \in \mathbb{N}, n \geq 2$, there exist $1 \leq m \leq n$ such that

$$
d\left(y_{n}, y_{n-1}\right) \preceq \lambda^{n-1} d\left(y_{0}, y_{m}\right) .
$$

For the proof of inequality (2.3), we use the following relation:

$$
d\left(y_{n}, y_{n-1}\right) \preceq \lambda^{n-1} d\left(y_{n-1}, y_{n-2}\right) \text { or } d\left(y_{n}, y_{n-1}\right) \preceq \lambda^{n-1} d\left(y_{n-2}, y_{n}\right) .
$$

Indeed, according to (2.1), we have

$$
d\left(y_{n}, y_{n-1}\right)=d\left(f x_{n}, f x_{n-1}\right) \preceq \lambda \cdot u_{n, n-1},
$$

where

$$
\begin{aligned}
& u_{n, n-1} \\
\in & \left\{d\left(g x_{n}, g x_{n-1}\right), d\left(g x_{n}, f x_{n}\right), d\left(g x_{n-1}, f x_{n-1}\right), d\left(g x_{n}, f x_{n-1}\right), d\left(g x_{n-1}, f x_{n}\right)\right\} \\
= & \left\{d\left(y_{n-1}, y_{n-2}\right), d\left(y_{n-1}, y_{n}\right), d\left(y_{n-2}, y_{n-1}\right), d\left(y_{n-1}, y_{n-1}\right), d\left(y_{n-2}, y_{n}\right)\right\} \\
= & \left\{d\left(y_{n-1}, y_{n-2}\right), d\left(y_{n-1}, y_{n}\right), \theta, d\left(y_{n-2}, y_{n}\right)\right\} .
\end{aligned}
$$

Since, $y_{n} \neq y_{n+1}$ for all $n \geq 0$ it follows that $u_{n, n-1} \in\left\{d\left(y_{n-1}, y_{n-2}\right), d\left(y_{n-2}, y_{n}\right)\right\}$. Hence, (2.4) holds.

Following the arguments given in the proof of [15, Theorem 2.1], we can prove (2.3). This means that for each $a, b \in\left\{y_{0}, y_{1}, y_{2}, \ldots\right\}$ there exists $\delta\left(x_{0}\right) \in P$ such that $d(a, b) \preceq \delta\left(x_{0}\right)$ where $\delta\left(x_{0}\right)=\left(\prod_{i=1}^{\infty} \frac{1+\lambda^{i}}{1-\lambda^{i}}\right) d\left(y_{0}, y_{1}\right)$.

Based on this we get that $\left\{y_{n}\right\}$ is a Cauchy sequence. Indeed, for $k>n \geq 1$

$$
\begin{aligned}
d\left(y_{n}, y_{k}\right) & \preceq d\left(y_{n}, y_{n+1}\right)+d\left(y_{n+1}, y_{n+2}\right)+\cdots+d\left(y_{k-1}, y_{k}\right) \\
& \preceq \lambda^{n} d\left(y_{0}, y_{m_{1}}\right)+\lambda^{n+1} d\left(y_{0}, y_{m_{2}}\right)+\cdots+\lambda^{k-1} d\left(y_{0}, y_{m_{k}}\right) \\
& \preceq\left(\lambda^{n}+\lambda^{n+1}+\cdots+\lambda^{k-1}\right) \delta\left(x_{0}\right) \\
& =\lambda^{n} \frac{1-\lambda^{k-n}}{1-\lambda} \delta\left(x_{0}\right) \preceq \frac{\lambda^{n}}{1-\lambda} \delta\left(x_{0}\right) \rightarrow \theta, \text { as } n \rightarrow \infty .
\end{aligned}
$$

By properties $\left(\mathrm{p}_{5}\right)$ and $\left(\mathrm{p}_{4}\right)$ it follows that $\left\{y_{n}\right\}$ is a Cauchy sequence. Therefore, $y_{n} \rightarrow g z \in g X$ for some $z \in X$.

We shall prove that $f z=g z$. Taking $x=x_{n}, y=z$ in (2.1) we get

$$
d\left(f x_{n}, f z\right) \preceq \lambda \cdot u_{n},
$$

where

$$
u_{n} \in\left\{d\left(g x_{n}, g z\right), d\left(g x_{n}, f x_{n}\right), d(g z, f z), d\left(g x_{n}, f z\right), d\left(g z, f x_{n}\right)\right\} .
$$

Letc, $\theta \ll c$, be given. Then we have the following cases:

$1^{0} d\left(f x_{n}, f z\right) \preceq \lambda \cdot d\left(g x_{n}, g z\right) \ll \lambda \frac{c}{\lambda}=c$, for $n>n_{0}=n_{0}(c)$.

$2^{0} d\left(f x_{n}, f z\right) \preceq \lambda \cdot d\left(g x_{n}, f x_{n}\right) \ll \lambda \frac{c}{\lambda}=c$, for $n>n_{1}=n_{1}(c)$.

$3^{0} d\left(f x_{n}, f z\right) \preceq \lambda \cdot d(g z, f z) \preceq \lambda d\left(g z, f x_{n}\right)+\lambda d\left(f x_{n}, f z\right) \Rightarrow d\left(f x_{n}, f z\right) \preceq$ $\frac{1}{1-\lambda} d\left(g z, f x_{n}\right) \ll \frac{1}{1-\lambda} \cdot(1-\lambda) c=\bar{c}$, for $n>n_{2}=n_{2}(c)$. 
$4^{0} d\left(f x_{n}, f z\right) \preceq \lambda \cdot d\left(g x_{n}, f z\right) \preceq \lambda d\left(g x_{n}, f x_{n}\right)+\lambda d\left(f x_{n}, f z\right) \Rightarrow d\left(f x_{n}, f z\right) \preceq$ $\frac{\lambda}{1-\lambda} d\left(g x_{n}, f x_{n}\right) \ll \frac{\lambda}{1-\lambda} \cdot \frac{(1-\lambda) c}{\lambda}=c$, for $n>n_{3}=n_{3}(c)$.

$5^{0} d\left(f x_{n}, f z\right) \preceq \lambda \cdot d\left(g z, f x_{n}\right) \ll \lambda \frac{c}{\lambda}=c$, for $n>n_{4}=n_{4}(c)$.

Hence, $f x_{n} \rightarrow f z$, i.e., $f z=g z$ and $f, g$ have a coincidence point. Let $f z=$ $w=g z$. Since $f$ and $g$ are weakly compatible, then $g w=g f z=f g z=f w$.

Now we shall show that $f w=w$. For this we have

$$
d(w, f w)=d(f z, f w) \preceq \lambda \cdot u(z, w),
$$

where

$$
\begin{aligned}
u(z, w) & \in\{d(g z, g w), d(g z, f z), d(g w, f w), d(g z, f w), d(g w, f z)\} \\
& =\{d(f z, f w), \theta, \theta, d(f z, f w), d(f w, f z)\}=\{d(f z, f w), \theta\} .
\end{aligned}
$$

Hence, $d(f z, f w) \preceq \lambda \cdot d(f z, f w)$ or $d(f z, f w) \preceq \lambda \cdot \theta=\theta$, which implies that $f z=f w$, and $w$ is a common fixed point of $f$ and $g$.

For the proof of uniqueness, suppose that $w_{1}$ is also a fixed point of $f$ and $g$. Then from (2.1),

$$
d\left(w, w_{1}\right)=d\left(f w, f w_{1}\right) \preceq \lambda \cdot u\left(w, w_{1}\right),
$$

where

$$
\begin{aligned}
u\left(w, w_{1}\right) & \in\left\{d\left(g w, g w_{1}\right), d(g w, f w), d\left(g w_{1}, f w_{1}\right), d\left(g w, f w_{1}\right), d\left(g w_{1}, f w\right)\right\} \\
& =\left\{d\left(w, w_{1}\right), d(w, w), d\left(w_{1}, w_{1}\right), d\left(w, w_{1}\right), d\left(w_{1}, w\right)\right\}=\left\{d\left(w, w_{1}\right), \theta\right\} .
\end{aligned}
$$

Hence, we obtain that $d\left(w, w_{1}\right) \preceq \lambda \cdot d\left(w, w_{1}\right)$ or $d\left(w, w_{1}\right) \preceq \theta$, which implies that $w=w_{1}$.

Remark 2.3. Since $f z=w=g z$, it follows that $w$ is a point of coincidence of maps $f$ and $g$. If this point of coincidence is unique, then, by [1, Proposition 1.4], $w$ is the unique fixed point of $f$ and $g$.

To prove that this is the case, let $w_{1}$ be another point of coincidence of $f$ and $g$. This means that there exist $z$ and $z_{1}$ such that $f z=g z=w$ and $f z_{1}=g z_{1}=w_{1}$. Hence, we have

$$
d\left(w, w_{1}\right)=d\left(f z, f z_{1}\right) \preceq \lambda \cdot u\left(z, z_{1}\right),
$$

where

$$
\begin{aligned}
u\left(z, z_{1}\right) & \in\left\{d\left(g z, g z_{1}\right), d(g z, f z), d\left(g z_{1}, f z_{1}\right), d\left(g z, f z_{1}\right), d\left(g z_{1}, f z\right)\right\} \\
& =\left\{d\left(w, w_{1}\right), d(w, w), d\left(w_{1}, w_{1}\right), d\left(w, w_{1}\right), d\left(w_{1}, w\right)\right\}=\left\{d\left(w, w_{1}\right), \theta\right\} .
\end{aligned}
$$

Now, we get that $d\left(w, w_{1}\right) \preceq \lambda \cdot d\left(w, w_{1}\right)$ or $d\left(w, w_{1}\right) \preceq \lambda \cdot \theta=\theta$, which implies that $w=w_{1}$.

In the previous theorem the cone $P$ in ordered Banach space $E$ is only supposed to have non-empty interior (it is not necessarily normal). If $g=i_{X}$, identity mapping on $X$, we obtain a result from [15]. If $E=\mathbb{R}, P=[0,+\infty),\|\cdot\|=|\cdot|$, we obtain the results of Ćirić [4] if $g=i_{X}$ and Das-Naik [5] if $g \neq i_{X}$, for metric spaces. 
Example 2.4. This example verifies that Theorem 2.2 is a proper generalization of results from [5] and [8].

Let $X=[0,1], E=C_{\mathbb{R}}^{1}[0,1]$ with $\|x\|=\|x\|_{\infty}+\left\|x^{\prime}\right\|_{\infty}$ and $P=\{x \in E$ : $x(t) \geq 0\}$. Define $d: X \times X \rightarrow E$ by $d(x, y)(t):=|x-y| e^{t}$. It is easy to see that $d$ is a cone metric on $X$ and $(X, d)$ is a complete cone metric space. Take functions $f x=a x, g x=b x, 0<a<b<1$ which map the set $X$ into $X$. The mapping $f$ is a $g$-quasicontraction, but it is not a quasicontraction. Indeed, if $\lambda \in\left[\frac{a}{b}, 1\right)$ then for each $x, y \in X$ there exists $u(x, y)=d(g x, g y)$ such that

$$
d(f x, f y) \preceq \lambda \cdot u(x, y)=\lambda d(g x, g y) \Leftrightarrow|f x-f y| e^{t} \leq \lambda|g x-g y| e^{t} \Leftrightarrow a \leq \lambda b .
$$

The mappings $f$ and $g$ are weakly compatible since they commute at their fixed point $x=0$. All the conditions of Theorem 2.2 are fulfilled, and so the mappings $f$ and $g$ have a unique common fixed point $x=0$. On the other hand, since the cone $P$ is non-normal, in this case it is not possible to apply results from [5] and [8].

Remark 2.5. Let $\bar{y}=g z=\lim _{k \rightarrow \infty} y_{k}$. Then we have the following estimate for the distance between $y_{n}, n \in \mathbb{N}$ and $\bar{y}$ :

$$
d\left(y_{n}, \bar{y}\right) \preceq \frac{\lambda^{n}}{1-\lambda} \delta\left(x_{0}\right) .
$$

Indeed,

$$
d\left(y_{n}, \bar{y}\right) \preceq d\left(y_{n}, y_{k}\right)+d\left(y_{k}, \bar{y}\right) \preceq \frac{\lambda^{n}}{1-\lambda} \delta\left(x_{0}\right)+d\left(y_{k}, \bar{y}\right) .
$$

Since, $y_{k} \rightarrow \bar{y}$ as $k \rightarrow \infty$ then for each $c \in \operatorname{int} P$ there exists $k_{0}$ such that $k>k_{0}$ : $d\left(y_{k}, \bar{y}\right) \ll c$. Now, according to property $\left(\mathrm{p}_{3}\right)$, we obtain that

$$
d\left(y_{n}, \bar{y}\right) \preceq \frac{\lambda^{n}}{1-\lambda} \delta\left(x_{0}\right) .
$$

2.2. Hardy-Rogers-type results. Our next theorem extends and slightly improves Theorem 2.8 and Corollaries 2.10-2.12 from [3].

Theorem 2.6. Let $f, g, S$ and $T$ be self-maps on a cone metric space $(X, d)$ with a solid cone, satisfying that $f(X) \subset T(X), g(X) \subset S(X)$ and

$$
d(f x, g y) \preceq p d(S x, T y)+q d(f x, S x)+r d(g y, T y)+s d(f x, T y)+t d(g y, S x)
$$

for all $x, y \in X$, where $p, q, r, s, t$ are nonnegative real numbers with $p+q+r+s+$ $t<1$, and $q=r$ or $s=t$. If one of $f(X), g(X), S(X)$, or $T(X)$ is a complete subspace of $X$, then $\{f, S\}$ and $\{g, T\}$ have a unique point of coincidence in $X$. Moreover, if $\{f, S\}$ and $\{g, T\}$ are weakly compatible, then $f, g, S$ and $T$ have a unique common fixed point.

Proof. For an arbitrary point $x_{0} \in X$, we construct sequences $\left\{x_{n}\right\}$ and $\left\{y_{n}\right\}$ in $X$ such that

$$
f x_{2 n-2}=T x_{2 n-1}=y_{2 n-1}, \text { and } g x_{2 n-1}=S x_{2 n}=y_{2 n} .
$$


We have from $(2.5)$,

$$
\begin{aligned}
d\left(y_{2 n+1}, y_{2 n+2}\right)= & d\left(f x_{2 n}, g x_{2 n+1}\right) \\
\preceq & p d\left(S x_{2 n}, T x_{2 n+1}\right)+q d\left(f x_{2 n}, S x_{2 n}\right)+r d\left(g x_{2 n+1}, T x_{2 n+1}\right) \\
& +s d\left(f x_{2 n}, T x_{2 n+1}\right)+t d\left(g x_{2 n+1}, S x_{2 n}\right) \\
= & p d\left(y_{2 n}, y_{2 n+1}\right)+q d\left(y_{2 n+1}, y_{2 n}\right)+r d\left(y_{2 n+2}, y_{2 n+1}\right) \\
& +s d\left(y_{2 n+1}, y_{2 n+1}\right)+t d\left(y_{2 n+2}, y_{2 n}\right),
\end{aligned}
$$

and so

$$
d\left(y_{2 n+1}, y_{2 n+2}\right) \preceq \frac{p+q+t}{1-r-t} d\left(y_{2 n}, y_{2 n+1}\right) .
$$

Also

$$
\begin{aligned}
d\left(y_{2 n+1}, y_{2 n}\right)= & d\left(f x_{2 n}, g x_{2 n-1}\right) \\
\preceq & p d\left(S x_{2 n}, T x_{2 n-1}\right)+q d\left(f x_{2 n}, S x_{2 n}\right)+r d\left(g x_{2 n-1}, T x_{2 n-1}\right) \\
& +s d\left(f x_{2 n}, T x_{2 n-1}\right)+t d\left(g x_{2 n-1}, S x_{2 n}\right) \\
= & p d\left(y_{2 n}, y_{2 n-1}\right)+q d\left(y_{2 n+1}, y_{2 n}\right)+r d\left(y_{2 n}, y_{2 n-1}\right) \\
& +s d\left(y_{2 n+1}, y_{2 n-1}\right)+t d\left(y_{2 n}, y_{2 n}\right)
\end{aligned}
$$

i.e.,

$$
d\left(y_{2 n+1}, y_{2 n}\right) \preceq \frac{p+r+s}{1-q-s} d\left(y_{2 n}, y_{2 n-1}\right) .
$$

Now by induction, we get that, for each $n$

$$
\begin{aligned}
d\left(y_{2 n+1}, y_{2 n+2}\right) & \preceq \frac{p+q+t}{1-r-t} d\left(y_{2 n}, y_{2 n+1}\right) \preceq \frac{p+q+t}{1-r-t} \frac{p+r+s}{1-q-s} d\left(y_{2 n-1}, y_{2 n}\right) \\
& \preceq \frac{p+q+t}{1-r-t} \frac{p+r+s}{1-q-s} \frac{p+q+t}{1-r-t} d\left(y_{2 n-2}, y_{2 n / 1}\right) \\
& \preceq \cdots \preceq \frac{p+q+t}{1-r-t}\left(\frac{p+r+s}{1-q-s} \frac{p+q+t}{1-r-t}\right)^{n} d\left(y_{0}, y_{1}\right),
\end{aligned}
$$

and

$$
\begin{aligned}
d\left(y_{2 n}, y_{2 n+1}\right) & \preceq \frac{p+r+s}{1-q-s} d\left(y_{2 n}, y_{2 n-1}\right) \preceq \frac{p+r+s}{1-q-s} \frac{p+q+t}{1-r-t} d\left(y_{2 n-1}, y_{2 n-2}\right) \\
& \preceq \cdots \preceq\left(\frac{p+r+s}{1-q-s} \frac{p+q+t}{1-r-t}\right)^{n} d\left(y_{0}, y_{1}\right) .
\end{aligned}
$$

Let $a=\frac{p+q+t}{1-r-t}, b=\frac{p+r+s}{1-q-s}$. If $q=r$, then

$$
a \cdot b=\frac{p+q+t}{1-q-t} \frac{p+r+s}{1-q-s}=\frac{p+q+t}{1-r-s} \frac{p+q+s}{1-r-t}<1 \cdot 1=1,
$$

and if $s=t$, then

$$
a \cdot b=\frac{p+q+t}{1-q-t} \frac{p+r+s}{1-q-s}=\frac{p+q+t}{1-q-s} \frac{p+r+s}{1-q-t}<1 \cdot 1=1 .
$$


Now, for $n<m$, we have

$$
\begin{aligned}
d\left(y_{2 n+1}, y_{2 m+1}\right) & \preceq d\left(y_{2 n+1}, y_{2 n+2}\right)+d\left(y_{2 n+2}, y_{2 n+3}\right)+\cdots+d\left(y_{2 m}, y_{2 m+1}\right) \\
& \preceq\left(a \sum_{i=n}^{m-1}(a b)^{i}+\sum_{i=n+1}^{m}(a b)^{i}\right) d\left(y_{0}, y_{1}\right) \\
& \preceq\left(\frac{a(a b)^{n}}{1-a b}+\frac{(a b)^{n+1}}{1-a b}\right) d\left(y_{0}, y_{1}\right)=(1+b) \frac{a(a b)^{n}}{1-a b} d\left(y_{0}, y_{1}\right) .
\end{aligned}
$$

Similarly, we obtain

$$
\begin{aligned}
d\left(y_{2 n}, y_{2 m+1}\right) & \preceq(1+a) \frac{(a b)^{n}}{1-a b} d\left(y_{0}, y_{1}\right), \\
d\left(y_{2 n}, y_{2 m}\right) & \preceq(1+a) \frac{(a b)^{n}}{1-a b} d\left(y_{0}, y_{1}\right), \\
d\left(y_{2 n+1}, y_{2 m}\right) & \preceq(1+b) \frac{a(a b)^{n}}{1-a b} d\left(y_{0}, y_{1}\right) .
\end{aligned}
$$

Hence, there exists $p>0$ such that for $p<n<m$,

$$
d\left(y_{n}, y_{m}\right) \preceq \max \left\{(1+a) \frac{(a b)^{p}}{1-a b},(1+b) \frac{a(a b)^{p}}{1-a b}\right\} d\left(y_{0}, y_{1}\right) \rightarrow \theta \text {, as } p \rightarrow \infty .
$$

According to properties $\left(\mathrm{p}_{5}\right)$ and $\left(\mathrm{p}_{4}\right)\left\{y_{n}\right\}$ is a Cauchy sequence. Suppose that $S(X)$ is complete. Then there exists a point $u$ in $S(X)$ such that $S x_{2 n}=y_{2 n} \rightarrow u$ as $n \rightarrow \infty$. Consequently, we can find $v$ in $X$ such that $S v=u$.

Now we shall show that $f v=u$. Using (2.5),

$$
\begin{aligned}
d(f v, u) \preceq & d\left(f v, g x_{2 n-1}\right)+d\left(g x_{2 n-1}, u\right) \\
\preceq & p d\left(S v, T x_{2 n-1}\right)+q d(f v, S v)+r d\left(g x_{2 n-1}, T x_{2 n-1}\right) \\
& +s d\left(f v, T x_{2 n-1}\right)+t d\left(g x_{2 n-1}, S v\right)+d\left(g x_{2 n-1}, u\right) .
\end{aligned}
$$

This implies that

$$
d(f v, u) \preceq \frac{1+r+s}{1-q-s} d\left(u, T x_{2 n-1}\right)+\frac{1+r+t}{1-q-s} d\left(g x_{2 n-1}, u\right) .
$$

Let $\theta \ll c$ be given. Since $y_{n} \rightarrow u$, there exists $N=N(c)$ such that for each $n>N$ we have that

$$
d\left(u, T x_{2 n-1}\right) \ll \frac{1-q-s}{1+r+s} \frac{c}{2} \text { and } d\left(g x_{2 n-1}, u\right) \ll \frac{1-q-s}{1+r+t} \frac{c}{2},
$$

which implies that $d(f v, u) \ll c$. By property $\left(\mathrm{p}_{2}\right)$ it follows that $f v=u$.

Since $u \in T(X)$, we can find a point $w$ in $X$ such that $T w=u$. Now we shall show that $g w=u$. Using (2.5), we have

$$
\begin{aligned}
d(g w, u) \preceq & d\left(f x_{2 n}, g w\right)+d\left(f x_{2 n}, u\right) \\
\preceq & d\left(f x_{2 n}, u\right)+p d\left(S x_{2 n}, T w\right)+q d\left(f x_{2 n}, S x_{2 n}\right) \\
& +r d(g w, T w)+s d\left(f x_{2 n}, T w\right)+t d\left(g w, S x_{2 n}\right)
\end{aligned}
$$

and so

$$
d(g w, u) \preceq \frac{1+q+s}{1-r-t} d\left(f x_{2 n}, u\right)+\frac{p+q+t}{1-r-t} d\left(S x_{2 n}, u\right) .
$$


Following arguments similar to those given above, we obtain $d(g w, u) \ll c$ for each $\theta \ll c$. Hence, $g w=T w=f v=S v=u$. If the pairs $\{f, S\}$ and $\{g, T\}$ are weakly compatible, then

$$
\begin{aligned}
& f u=f S v=S f v=S u=w_{1}(\text { say), and } \\
& g u=g T w=T g w=T u=w_{2}(\text { say). }
\end{aligned}
$$

Again, using (2.5),

$$
\begin{aligned}
d\left(w_{1}, w_{2}\right) & =d(f u, g u) \\
& \preceq p d(S u, T u)+q d(f u, S u)+r d(g u, T u)+s d(f u, T u)+t d(g u, S u) \\
& =p d\left(w_{1}, w_{2}\right)+q \cdot \theta+r \cdot \theta+s d\left(w_{1}, w_{2}\right)+t d\left(w_{1}, w_{2}\right) \\
& =(p+s+t) d\left(w_{1}, w_{2}\right),
\end{aligned}
$$

which implies $w_{1}=w_{2}$. Therefore $f u=g u=S u=T u$. Now we show that $u=g u$. Using (2.5),

$$
\begin{aligned}
d(u, g u) & =d(f v, g u) \\
& \preceq p d(S v, T u)+q d(f v, S v)+r d(g u, T u)+s d(f v, T u)+t d(g u, S v) \\
& =(p+s+t) d(u, g u),
\end{aligned}
$$

which implies that $g u=u$. Hence, $u$ is a common fixed point of $f, g, S$ and $T$. Clearly, (2.5) implies the uniqueness of common fixed point. The proofs for the cases when $g(X), f(X)$ or $T(X)$ is complete are similar, and therefore are omitted.

The following corollary extends and improves results in [2] and [14].

Corollary 2.7. Let $f, g$ and $T$ be self-maps on a cone metric space $(X, d)$ over a solid cone, satisfying $f(X) \cup g(X) \subset T(X)$ and

$$
d(f x, g y) \preceq p d(T x, T y)+q d(f x, T x)+r d(g y, T y)+s d(f x, T y)+t d(g y, T x)
$$

for all $x, y \in X$, where $p, q, r, s, t$ are nonnegative real numbers with $p+q+r+$ $s+t<1$, and $q=r$ or $s=t$. If one of $f(X), g(X)$ or $T(X)$ is a complete subspace of $X$, then $\{f, T\}$ and $\{g, T\}$ have a unique point of coincidence in $X$. Moreover, if $\{f, T\}$ and $\{g, T\}$ are weakly compatible, then $f, g$ and $T$ have a unique common fixed point.

The following two corollaries extend and improve results in [1] and [11]. Note that the case of ordered cone metric spaces and weakly increasing functions was treated in $[12$.

Corollary 2.8. Let $f$ and $T$ be self-maps on a cone metric space $(X, d)$ over a solid cone, satisfying $f(X) \subset T(X)$ and

$$
d(f x, f y) \preceq p d(T x, T y)+q d(f x, T x)+r d(f y, T y)+s d(f x, T y)+t d(f y, T x)
$$

for all $x, y \in X$, where $p, q, r, s, t$ are nonnegative real numbers with $p+q+r+s+$ $t<1$. If one of $f(X)$ or $T(X)$ is a complete subspace of $X$, then $f$ and $T$ have a unique point of coincidence in $X$. Moreover, if $f$ and $T$ are weakly compatible, then $f$ and $T$ have a unique common fixed point. 
Corollary 2.9. Let $f$ be a self-map on a cone metric space $(X, d)$ over a solid cone, satisfying

$$
d(f x, f y) \preceq p d(x, y)+q d(f x, x)+r d(f y, y)+s d(f x, y)+t d(f y, x)
$$

for all $x, y \in X$, where $p, q, r, s, t$ are nonnegative real numbers with $p+q+r+$ $s+t<1$. If $f(X)$ is a complete subspace of $X$, then $f$ has a unique fixed point in $X$.

\section{REFERENCES}

[1] M. Abbas and G. Jungck, Common Fixed point results of noncommuting mappings without continuity in cone metric spaces, J. Math. Anal. Appl., 341 (2008), 418-420.

[2] M. Abbas and B. E. Rhoades, Fixed and periodic point results in cone metric spaces, Appl. Math. Lett., 22 (2009), 511-515.

[3] M. Abbas, B. E. Rhoades and T. Nazir, Common fixed points for four maps in cone metric spaces, Appl. Math. Comput., 216 (2010), 80-86.

[4] Lj. B. Ćirić, A generalization of Banach's contraction principle, Proc. Amer. Math. Soc., 45 (1974), 267-273.

[5] K. M. Das and K. V. Naik, Common fixed point theorems for commuting maps on cone metric spaces, Proc. Amer. Math. Soc., 77 (1979), 369-373.

[6] K. Deimling, Nonlinear Functional Analysis, Springer-Verlag, 1985.

[7] L. G. Huang and X. Zhang, Cone metric spaces and fixed point theorems of contractive mappings, J. Math. Anal. Appl., 332 (2007), 1467-1475.

[8] D. Ilić and V. Rakočević, Common fixed points for maps on cone metric space, J. Math. Anal. Appl., 341 (2008), 876-882.

[9] D. Ilić and V. Rakočević, Quasi-contraction on cone metric space, Appl. Math. Lett. 22 (2009), 728-731.

[10] G. Jungck, Common fixed points for noncontinuous nonself maps on nonmetric spacers, Far East J. Math. Sci., f4 (1986), 199-215.

[11] G. Jungck, S. Radenović, S. Radojević and V. Rakočević, Common fixed point theorems for qeakly compatible pairs on cone metric spaces, Fixed Point Theory Appl., Vol. 2009, Article ID 643840, 13 pages, doi:10.1155/2009/643840.

[12] Z. Kadelburg, M. Pavlović and S. Radenović, Common fixed point theorems for ordered contractions and quasicontractions in ordered cone metric spaces, Comput. Math. Appl., 59 (2010), 3148-3159.

[13] Z. Kadelburg, S. Radenović and V. Rakočević, Remarks on "Quasi-contraction on a cone metric space", Appl. Math. Lett. 22 (2009), 1674-1679.

[14] Z. Kadelburg, S. Radenović and V. Rakočević, Topological vector space valued cone metric spaces and fixed point theorems, Fixed Point Theory Appl., in press.

[15] Sh. Rezapour, R. H. Haghi and N. Shahzad, Some notes on fixed points of quasi-contraction maps, Appl. Math. Lett., 23 (2010), 498-502.

${ }^{1}$ University of Belgrade, Faculty of Mathematics, Studentski trg 16, 11000 BeOgrad, Serbia.

E-mail address: kadelbur@matf.bg.ac.rs

${ }^{2}$ University of Belgrade, Faculty of Mechanical Engineering, Kraljice MaRiJe 16, 11120 Beograd, Serbia.

E-mail address: radens@beotel.net 